\title{
HOXA5 inhibits the proliferation and induces the apoptosis of cervical cancer cells via regulation of protein kinase $B$ and p27
}

\author{
ZEFEI WANG ${ }^{1}$, CHUNZHI YU ${ }^{2}$ and $\mathrm{HONG} \mathrm{WANG}^{3}$ \\ ${ }^{1}$ Department of Gynecology and Obstetrics, The Fourth People's Hospital of Shaanxi; ${ }^{2}$ Department of Obstetrics, \\ The Northwest Women's and Children's Hospital, Xi'an, Shaanxi 710000; ${ }^{3}$ Department of Oncology, \\ Tangdu Hospital, The Fourth Military Medical University, Xi'an, Shaanxi 710038, P.R. China
}

Received April 2,2018; Accepted September 27, 2018

DOI: $10.3892 /$ or.2018.6874

\begin{abstract}
Homeobox A5 (HOXA5) is a member of the homeobox gene (HOX) family, which plays an important role in the development of various malignant tumors. Here, we speculated that HOXA5 has an effect on cervical cancer development. In our study, we aimed to explore the role and molecular mechanism of HOXA5 in regards to the cell proliferation and apoptosis in cervical cancer. We found that expression levels of HOXA5 measured by RT-qPCR and western blot assays in cervical cancer cell lines and tissues were both significantly downregulated. We performed a gain-of-function experiment by the transfection with pcDNA.3.1-HOXA5 in ME-180 and HT- 3 cells to overexpress HOXA5, and the caspase- 3 activity measured by caspase-3 activity assay kit and cell apoptosis detected by flow cytometry were obviously promoted. Meanwhile, cell proliferation tested by BrdU assay, invasion determined by Transwell and cell viability tested by MTT were inhibited. Moreover, protein kinase B (AKT) was activated by incubation with SC79 (AKT activator; $1 \mu \mathrm{g} / \mathrm{ml}$ ) after HOXA5 overexpression, and reversed the effect of HOXA5 overexpression on p27 expression. Additionally, significant elevation of AKT activation measured by western blot analysis abrogated the effect of HOXA5 on caspase-3 activity, cell apoptosis, proliferation, invasion and cell viability. Taken together, this study revealed that HOXA5 inhibits cervical cancer progression
\end{abstract}

Correspondence to: Dr Hong Wang, Department of Oncology, Tangdu Hospital, The Fourth Military Medical University, 1 Xinsi Street, Xi'an, Shaanxi 710038, P.R. China

E-mail: wanghong_2018@126.com

Abbreviations: HOX, homeobox; AKT, protein kinase B; CDK, cyclin-dependent kinase; RT-qPCR, reverse-transcription polymerase chain reaction; PVDF, polyvinylidene fluoride; Annexin V-FITC, Annexin V-fluorescein isothiocyanate; PI, propidium iodide; MTT, 3-(4,5-dimethylthiazol-2-yl)-2,5-diphenyltetrazolium bromide; PBS, phosphate-buffered saline; OD, optical density; BrdU, bromodeoxyuridine; $\mathrm{SD}$, standard deviation

Key words: homeobox 5, cervical cancer, proliferation, apoptosis, protein kinase B, p27 by regulating $\mathrm{AKT} / \mathrm{p} 27$, proposing the potential role of HOXA5 in the prevention and treatment of cervical cancer.

\section{Introduction}

Cervical cancer is one of the most commonly diagnosed malignancies in the world (1). The mortality rate associated with cervical cancer is the highest among all female reproductive tract malignant tumors, and cervical cancer seriously threatens the health of women worldwide $(2,3)$. Although improvements in preventative measures and expansion of cervical cancer screening have significantly diminished the incidence and mortality rate in the developed world, there is a lack of cervical cancer screening in developing countries (4). Cervical cancer has a poor prognosis due to local invasion and lymphatic metastasis (5). Thus, it is necessary to investigate the biological mechanisms driving cervical cancer to provide novel insight into the prevention and therapeutic management of this disease.

The expression and dysfunction of homeobox (HOX) genes play an important role in the development of various malignant tumors, such as lung cancer, breast cancer, colon cancer, prostate cancer and leukemia (6-9). HOXA5 is a member of HOX gene family and is a transcriptional regulator that regulates cell growth, differentiation and apoptosis $(10,11)$. As the HOX genes have become a 'hot topic' in cancer research, more researchers have paid close attention concerning the relationship between HOXA5 and multiple malignancies in recent years. It has been found that lack of HOXA5 function and other genetic damage can lead to breast cancer development (12). It has been reported that HOXA5 induces cell apoptosis and decreases cell drug resistance in breast cancer, lung cancer and glioblastoma $(13,14)$. Moreover, a reduction in HOXA5 expression was recognized to be closely related to cell proliferation and invasion in tumors such as non-small cell lung cancer and esophageal squamous $(15,16)$. However, the role of HOXA5 in cervical carcinoma development still remains unclear. In the present study, we aimed to investigate and acquire insight into the molecular mechanisms of HOXA5 in cervical cancer to improve treatment of the disease.

Protein kinase B (AKT) is a homologue of v-AKT, a proto-oncogene that exists in human chromosomes (17). A variety of hormones, growth factors and cytokines can stimulate Akt activation, thereby regulating cell growth, proliferation, motility, invasion, apoptosis and other processes (18). Studies 
have indicated that phosphorylation of AKT is increased in prostate, breast and cervical cancer cells (19-21). AKT was found to induce cell proliferation and survival in $\beta$ cells, endothelial cells, cardiomyocytes and tumor cells $(21,22)$. It has been reported that AKT activation can be constrained by HOXA5 in mouse white adipocytes (13). Nevertheless, the effect of HOXA5 on AKT phosphorylation in cervical cancer cells remains unknown. In our study, we explored the correlation between HOXA5 and AKT phosphorylation in cervical cancer. p27 is an important member of the p21 family of cyclin-dependent kinase inhibitors and is a broad-spectrum cyclin-dependent kinase (CDK) inhibitor that blocks the cell cycle through the transition point into the $\mathrm{S}$ phase, and then inhibits cell growth and proliferation, and is widely recognized as a tumor-suppressor gene in various types of cancer, including cervical cancer (23-25). Moreover, p27 expression could be regulated via AKT activation (26) and thus we hypothesized that HOXA5 regulates cell proliferation and apoptosis via AKT/p27 in cervical cancer.

We aimed to probe into the molecular mechanisms of HOXA5 in cervical cancer by assessing the expression of HOXA5 in cervical cancer cells. We investigated the cell proliferation and apoptosis in cervical cancer cell lines after overexpressing HOXA5. We also investigated the molecular mechanism of cell proliferation and apoptosis following the overexpression of HOXA5 in cervical cancer.

\section{Materials and methods}

Cell culture and tissues. The cervical cancer cell lines ME-180 (cat. no. HTB-33 ${ }^{\mathrm{TM}}$ ), HT-3 (cat. no. HTB-32 ${ }^{\mathrm{TM}}$ ), HeLa (cat. no. CCL-2 ${ }^{\mathrm{TM}}$ ) and SiHa (cat. no. HTB-35 ${ }^{\mathrm{TM}}$ ) (ATCC; Manassas, VA, USA) were grown in Dulbecco's modified Eagle's medium (HyClone; GE Healthcare Life Sciences, Logan, UT, USA) supplemented with $10 \%$ fetal bovine serum (FBS; HyClone; GE Healthcare Life Sciences), $100 \mathrm{U} / \mathrm{ml}$ of penicillin, and $100 \mu \mathrm{g} / \mathrm{ml}$ of streptomycin. Human cervical epithelial cells (HCerEpiC; ScienCell Research Laboratories, Carlsbad, CA, USA; cat. no. CP7060) (27), were cultured in cervical epithelial cell medium (ScienCell Research Laboratories). Cells were cultured in an atmosphere of $5 \% \mathrm{CO}_{2}$ at $37^{\circ} \mathrm{C}$.

Cervical tumor samples $(n=10,40-50$ years of age) were collected in the Fourth People's Hospital of Shaanxi from women with the average year of 42 years undergoing hysterectomies without having been treated with radiotherapy or chemotherapy. Two patients had a diagnosis of squamous cell carcinoma (SCC), 6 presented with adenomatous carcinoma (ADC) and 2 patients had an intermediate diagnosis of adenosquamous cell carcinoma (ASC). Normal tissues $(n=10$, 40-50 years of age) were collected in the Fourth People's Hospital of Shaanxi from women with the average year of 45 years old undergoing surgery for myoma or adenomyoma. Normal tissue samples were non-malignant and negative for human papilloma virus and ThinPrep cytologic tests. The collections were performed between August 2017 and September 2017 and were approved by the Ethics Committee of The Fourth People's Hospital of Shaanxi. Informed consent was obtained from all of the patients.

RT-qPCR assay. Total RNA of cells was extracted by using TRizol (Gibco; Thermo Fisher Scientific, Inc., Waltham,
MA, USA) and reverse-transcribed into cDNA using the PrimeScript $^{\mathrm{TM}}$ First Strand cDNA Synthesis kit (Takara Biotechnology Co., Ltd., Dalian, China). The volume of reverse-transcription polymerase chain reaction (RT-qPCR) was $20 \mu \mathrm{l}$ and it contained $10 \mu \mathrm{l}$ SYBR Premix Ex Taq II (Takara Biotechnology Co., Ltd.). The primers were as follows: HOXA5, sense primer: 5'-AGCCACAAATCAAGGACACA-3' and antisense primer: 5'-GCTCGCTCACGGAACTATG-3'; GAPDH, sense primer: 5'-CGAAGGTGAAGGTCGGAGT-3' and antisense primer: 5'-GAAGATGGTGATGGGATTTC-3'. The cycling parameters consisted of $94^{\circ} \mathrm{C}$ for $30 \mathrm{sec} ; 40$ cycles of $94^{\circ} \mathrm{C}$ for $40 \mathrm{sec}, 60^{\circ} \mathrm{C}$ for $30 \mathrm{sec}$ and $72^{\circ} \mathrm{C}$ for $30 \mathrm{sec}$ and $72^{\circ} \mathrm{C}$ for $10 \mathrm{~min}$. The relative levels of gene expression were quantified using the $2^{-\Delta \Delta C t}$ method (28). GAPDH was the reference gene. The experiment was repeated three times.

Western blot analysis. Cells were treated with lysate and protein was extracted. Then, the protein was quantified with a BCA kit (Beyotime Institute of Biotechnology, Nantong, China). After loading $25 \mu \mathrm{g}$ of the protein onto gel for $12 \%$ sodium dodecyl sulfate-polyacrylamide gel electrophoresis (SDS-PAGE), the proteins were separated and transferred onto polyvinylidene fluoride (PVDF) membranes (Bio-Rad Laboratories, Hercules, CA, USA) by electrophoretic transfer. The PVDF membranes were then incubated with $5 \%$ skim milk for $1.5 \mathrm{~h}$, followed by incubation overnight at $4{ }^{\circ} \mathrm{C}$ with the primary antibodies (all from Abcam Inc., Cambridge, MA, USA): anti-HOXA5 (dilution 1:800; cat. no. ab82645) anti-AKT (dilution 1:500; cat. no. ab8805), anti-Akt (phospho S473) (dilution 1:600; cat. no. ab81283), anti-p27 (dilution 1:1,000; cat. no. ab32034) and anti-GAPDH (dilution 1:500; cat. no. ab9485). Next, the polyvinylidene fluoride was incubated with a secondary antibody (dilution 1:800; cat. no. ab7090) diluted in the blocking buffer. Finally, the protein was detected using enhanced chemiluminescence. The experiment was repeated three times.

Construction of the recombinant plasmids. The full-length HOXA5 gene (GenBank ${ }^{\mathrm{TM}}$ accession number NM_019102.3) was amplified using RT-PCR, followed by insertion into the plasmid pcDNA.3.1 (Clontech Inc., Palo Alto, CA, USA). The restriction enzymes used for the cDNA and plasmid pcDNA.3.1 were EcoRI and BamHI. The recombinant plasmid was then transducted into Escherichia coli $\mathrm{DH} 5 \alpha$ cells (Tiangen, Beijing, China), followed by amplification at $37^{\circ} \mathrm{C}$. Afterwards, the recombinant plasmids were extracted using a plasmid DNA extraction kit (Takara Biotechnology Co., Ltd.). The recombinant plasmid containing the correct sequence was named pcDNA.3.1-HOXA5.

Cell transfection. The ME-180 and HT-3 cell lines were separately cultured in 96-well plates and incubated in an incubator (Thermo Fisher Scientific, Inc.) with $5 \% \mathrm{CO}_{2}$ for $24 \mathrm{~h}$. The cells were transfected with pcDNA.3.1-HOXA5 $(0.2 \mu \mathrm{g})$, pcDNA.3.1 $(0.2 \mu \mathrm{g})$ or pcDNA.3.1-p27 $(0.2 \mu \mathrm{g})$ using Turbofect $(0.5 \mu \mathrm{l}$; Thermo Fisher Scientific, Inc.) and incubated at $37^{\circ} \mathrm{C}$ in $5 \% \mathrm{CO}_{2}$ for $24,36,48$ or $72 \mathrm{~h}$. Transfection efficiency was measured by RT-qPCR and western blot assays.

Flow cytometric analysis. Cell apoptosis was examined using an Annexin V-fluorescein isothiocyanate (FITC) and 


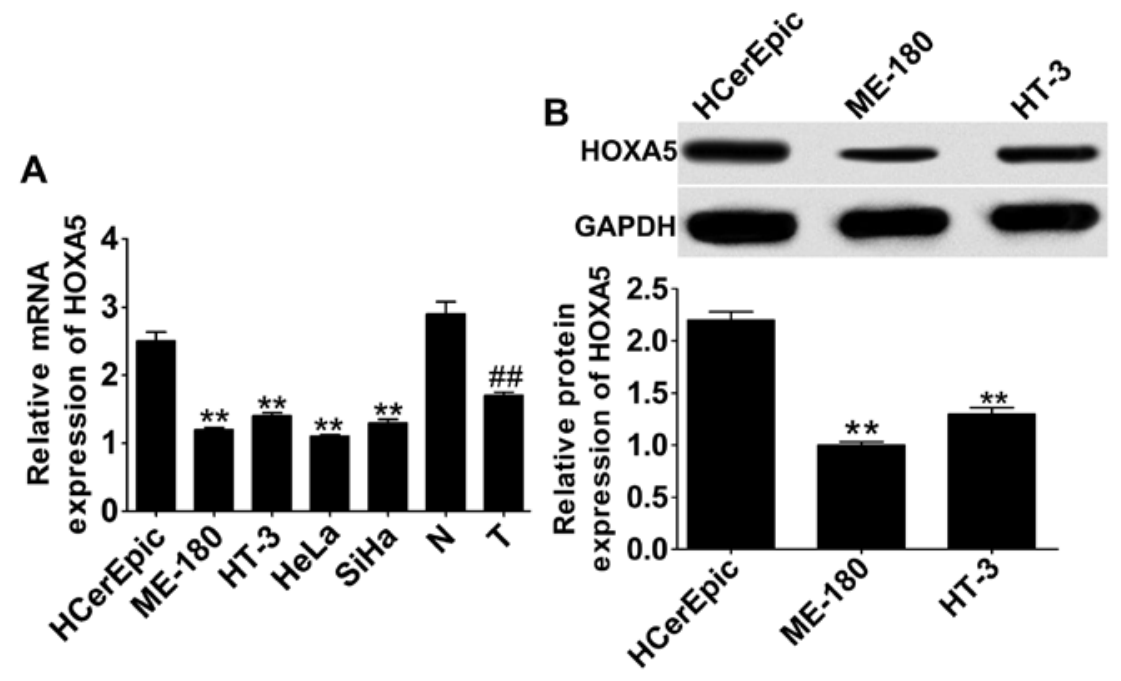

Figure 1. Relative expression of HOXA5 in cervical cancer cell lines. The relative mRNA (A) and protein (B) levels of HOXA5 were separately assessed by qRT-PCR and western blot analyses. HCerEpic, human cervical epithelial cells; ME-180, HT-3, HeLa and SiHa: Cervical cancer cell lines. GAPDH was the normalization gene. $n=3,{ }^{* * *} \mathrm{P}<0.01$ vs. the HCerEpic cells indicates a significant difference. $N$, normal cervical tissues; $T$, cervical cancer tissues. $n=10$, ${ }^{\# \#} \mathrm{P}<0.01$ vs. $\mathrm{N}$ group indicates a significant difference.

propidium iodide (PI) kit (Jiancheng Bioengineering Institute, Nanjing, China) in accordance with the supplier's instructions. Briefly, cells were harvested and centrifuged at $200 \mathrm{x}$ g for $5 \mathrm{~min}$. The cells $\left(5 \times 10^{5}\right.$ cells $\left./ \mathrm{ml}\right)$ were resuspended in the binding buffer and mixed with $5 \mu \mathrm{l}$ of Annexin V-FITC in $195 \mu \mathrm{l}$ of the cell suspension for $30 \mathrm{~min}$ at $4^{\circ} \mathrm{C}$. Afterwards, cells were incubated with PI $(6 \mu \mathrm{l})$ for $8 \mathrm{~min}$. The apoptotic cells were quantified by FACS analyzer (Beckman Coulter, Brea, CA, USA). The experiment was repeated three times.

Caspase-3 activity assay. Caspase- 3 activity in the cells was measured in line with the explanatory memorandum of a caspase-3 activity assay kit (Beyotime Institute of Biotechnology). In brief, cells $\left(1 \times 10^{6}\right)$ were centrifugated, washed trice with PBS and incubated in $500 \mu 1$ lysis buffer on ice for $15 \mathrm{~min}$. The activity of caspase- 3 was tested by a $200 \mathrm{mmol} / 1 \mathrm{AcDEVD}-\mathrm{MCA}$ fluorogenic substrate in the assay buffer, and fluorescence intensity was quantified with spectrofluorometry. The experiment was repeated three times.

Cell viability. 3-(4,5-Dimethylthiazol-2-yl)-2,5-diphenyltetrazolium bromide (MTT) assay was used to quantify cell viability according to the specifications. Firstly, cells were incubated in a 96-well plate in humid atmosphere of $5 \% \mathrm{CO}_{2}$ at $37^{\circ} \mathrm{C}$ for $24 \mathrm{~h}$ followed by transfection. MTT $(5 \mathrm{~g} / \mathrm{l})$ diluted in phosphate-buffered saline (PBS) was added and incubated at $37^{\circ} \mathrm{C}$ for $6 \mathrm{~h}$. Subsequently, dimethyl sulfoxide (DMSO) (160 $\mu \mathrm{l} / \mathrm{well})$ was added to dissolve the formazan, and the absorbance (OD) values were read using an microplate reader at $490 \mathrm{~nm}$ (Thermo Fisher Scientific, Inc.). The experiment was repeated three times.

Bromodeoxyuridine (BrdU) assay. Cell proliferation was tested using a BrdU kit (Roche Applied Science, Mannheim, Germany) on the basis of the instructions. Cells were plated in 96-well plates and transfections were performed. Cells were incubated with BrdU solution (10 $\mu \mathrm{l} /$ well) for $1.5 \mathrm{~h}$ and then denaturing solution $(100 \mu \mathrm{l} /$ well $)$ for $25 \mathrm{~min}$. Cells were then stained with anti-BrdU antibody for $1.5 \mathrm{~h}$ at room temperature followed by staining with secondary antibody solution. Next, $100 \mu 1$ of tetramethyl benzidine substrate was added and allowed to incubate for $30 \mathrm{~min}$. Finally, the results were detected at $450 \mathrm{~nm}$ using a SpectroFluor Plus multiwell plate reader (Tecan Group, Ltd., Mannedorf, Switzerland). The experiment was repeated three times.

Transwell invasion assays. Bio-Coat cell migration chambers (BD Biosciences, San Jose, CA, USA) were used to assess cervical cancer cell invasion. Chambers were coated with Matrigel (Becton Dickinson; BD Biosciences), and the transfected cells were suspended using $350 \mu \mathrm{l}$ serum-free medium ( $1 \times 10^{5}$ cells) and added to the top chamber. Then, the cells were cultured with $5 \% \mathrm{CO}_{2}$ at $37^{\circ} \mathrm{C}$ for $48 \mathrm{~h}$ followed by the addition of culture medium $(500 \mu \mathrm{l})$ with $10 \% \mathrm{FBS}$ to the lower chamber. Non-invading cells were gently removed using a cotton swab, and invasive cells were fixed with $95 \%$ ethanol and stained with trypan blue. The invasive cells were quantified as the mean count of stained cells in six random fields under bright field microscopy (x400 magnification) using an Olympus IX70 inverted microscope (Olympus Corp., Tokyo, Japan). The experiment was repeated three times.

Statistical analysis. Statistical significance was determined by the Student's t-test between two groups and by one-way ANOVA followed by a Bonferroni test for multiple groups. A P-value of $<0.05$ was considered to indicate a statistically significant result. Data are expressed as the mean \pm standard deviation (SD). Statistical analyses were processed with SPSS version 22.0 software (IBM Corp., Armonk, NY, USA).

\section{Results}

Downregulation of the expression of HOXA5 in cervical cancer. We quantified the expression of HOXA5 in cervical cancer cell lines and tissues to explore the expression of HOXA5 in cervical cancer. The results showed that mRNA expression (Fig. 1A) of HOXA5 as determined by RT-qPCR in cervical cancer cell 

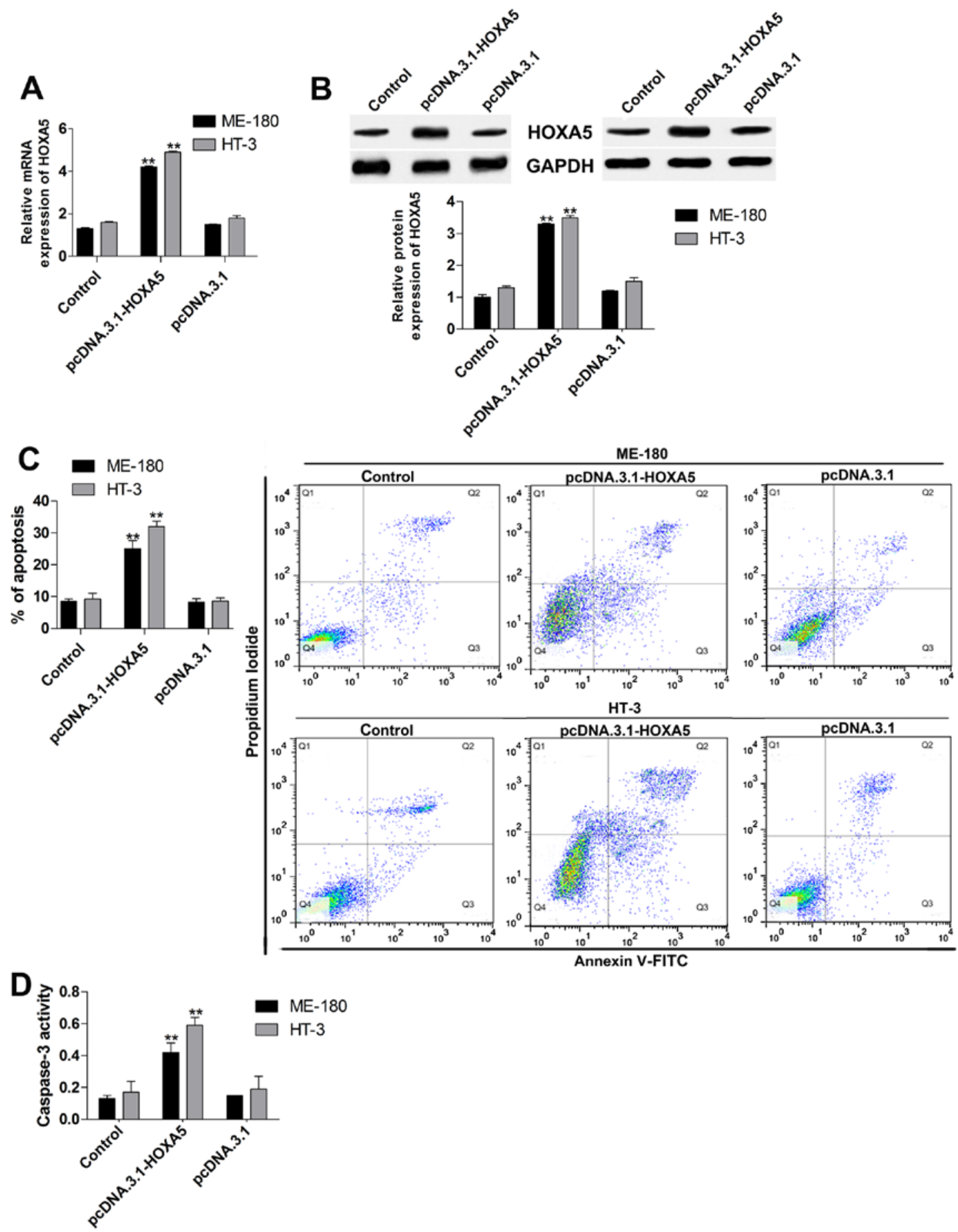

Figure 2. Effect of HOXA5 upregulation on cervical cancer cell apoptosis. The relative mRNA (A) and protein (B) levels of HOXA5 were separately measured by qRT-PCR and western blot analyses in cells treated with pcDNA.3.1-HOXA5. Apoptosis of ME-180 and HT-3 cells was determined by the Annexin V-FITC/PI assay (C) and caspase-3 activity (D) in cells treated with pcDNA.3.1-HOXA5. Control, cervical cancer cells; pcDNA.3.1-HOXA5, cervical cancer cells transfected with pcDNA.3.1-HOXA5 for $24 \mathrm{~h}$; pcDNA.3.1, cervical cancer cells transfected with pcDNA.3.1 for $24 \mathrm{~h}$. n=3, ${ }^{* * *} \mathrm{P}<0.01 \mathrm{vs}$. the pcDNA.3.1 group.

lines and tissues was significantly decreased in both when compared with human cervical epithelial HCerEpic cells and normal tissues. The mRNA reduction of HOXA5 in ME-180, HT-3, HeLa and SiHa cells exhibited no significant differences between each cell line; thus we detected the protein expression of HOXA5 in ME- 180 and HT-3 cells. The protein expression (Fig. 1B) of HOXA5 as determined by western blot analysis in ME-180 and HT-3 cells was also significantly decreased when compared with the HCerEPic cell line.
HOXA5 overexpression induces cell apoptosis in cervical cancer cell lines. To investigate the potential role of HOXA5 in cervical cancer, we measured cell apoptosis by using Annexin V-FITC/PI assay and caspase-3 activity testing after HOXA5 overexpression in ME-180 and HT-3 cells. Firstly, we overexpressed HOXA5 by cells transfection with pcDNA.3.1-HOXA5, and the data indicated that mRNA (Fig. 2A) and protein (Fig. 2B) expression of HOXA5 were both increased twice. Thus, the gain-of-function experiment of 

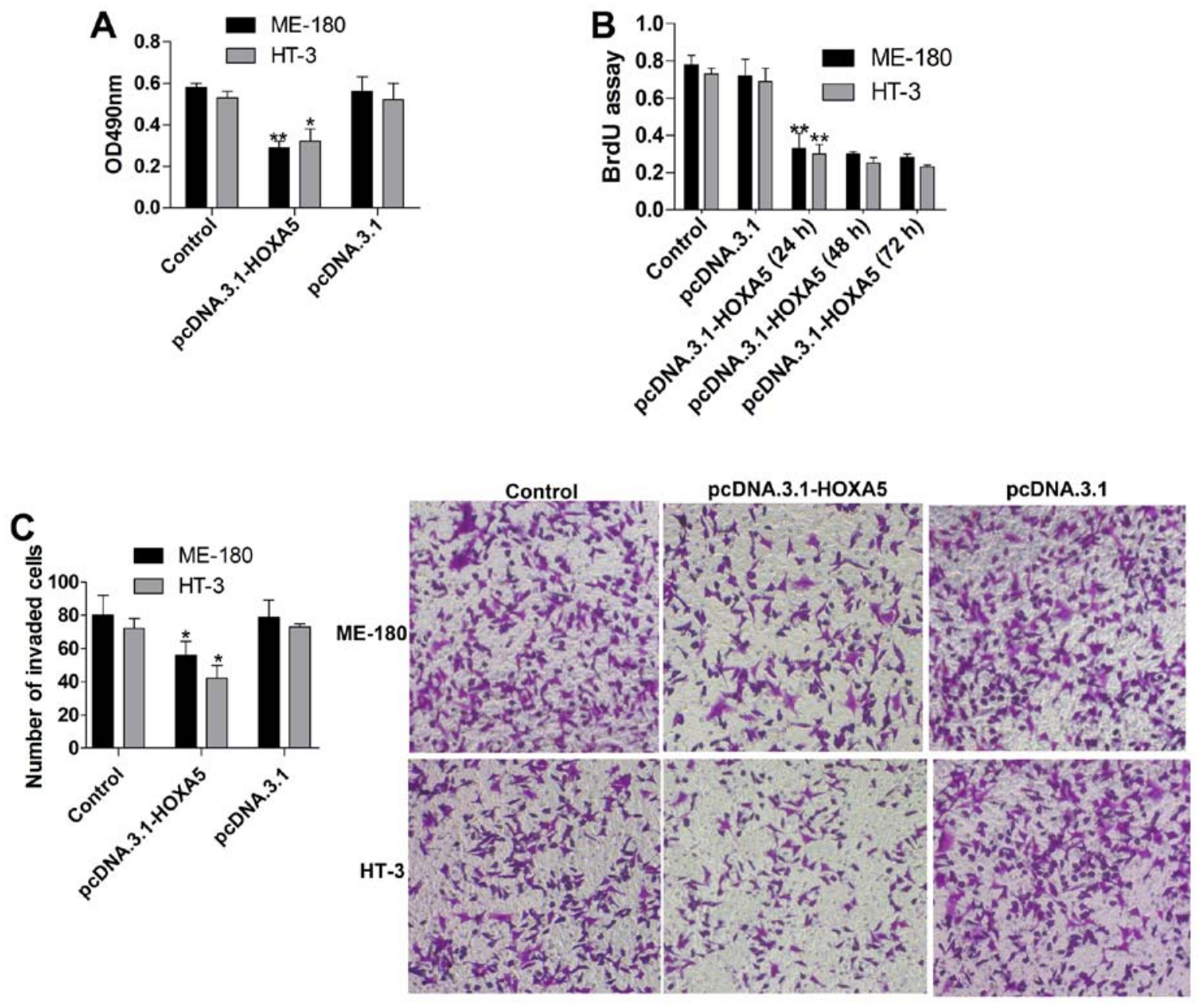

Figure 3. Effects of HOXA5 overexpression on proliferation and invasion in cervical cancer cells. The proliferation capacity was determined by MTT (A) and BrdU (B) assays in cells transfected with pcDNA.3.1-HOXA5. (C) Invasion was assessed in cells transfected with pcDNA.3.1-HOXA5 using the Transwell invasion assay. pcDNA.3.1-HOXA5 (24 h), cervical cancer cells transfected with pcDNA.3.1-HOXA5 for $24 \mathrm{~h}$; pcDNA.3.1-HOXA5 (48 h), cervical cancer cells transfected with pcDNA.3.1-HOXA5 for $48 \mathrm{~h}$; pcDNA.3.1-HOXA5 (72 h), cervical cancer cells transfected with pcDNA.3.1-HOXA5 for $72 \mathrm{~h}$. n=3, ${ }^{*} \mathrm{P}<0.05,{ }^{* *} \mathrm{P}<0.01$ vs. the pcDNA.3.1 group.

HOXA5 was successful. Subsequently, the effect of HOXA5 upregulation on cell apoptosis in ME-180 and HT-3 cells were tested. In the Annexin V-FITC/PI assay (Fig. 2C), cell apoptosis was significantly induced by upregulation of HOXA5. Moreover, caspase-3 activity (Fig. 2D) was also significantly facilitated after pcDNA.3.1-HOXA5 transfection.

HOXA5 overexpression suppresses cell proliferation and invasion in cervical cancer cell lines. To further estimate the influence of HOXA5 overexpression on cervical cancer, we tested cell viability and proliferation using MTT and BrdU assays, respectively. The results revealed that cell viability (Fig. 3A) was markedly suppressed in the pcDNA.3.1-HOXA5 group when compared to that noted in the pcDNA.3.1group. We also assessed the proliferation (Fig. 3B) of cells transfected with pcDNA.3.1-HOXA5 for 24,48 and $72 \mathrm{~h}$, and it was showed that the proliferation in the pcDNA.3.1-HOXA5 (24 h) group was significantly inhibited in contrast to the pcDNA.3.1 group, and the suppression was slightly time-dependent. Additionally, cell invasion (Fig. 3C) was detected by Transwell invasion assay, and the data showed a significant decrease in cell invasion after HOXA5 overexpression. Therefore, HOXA5 displayed a valid inhibitory effect on cell proliferation and invasion in cervical cancer cell lines.

Regulation of AKT activity and p27 expression by HOXA5. To gain insight into the molecular mechanisms of HOXA5 in cervical cancer, we determined the protein expression of p-AKT and p27 via western blot assay in ME-180 and HT-3 cells with HOXA5 upregulation. The results indicated that the protein level of p-AKT (Fig. 4) in the pcDNA.3.1-HOXA5 group was significantly reduced in contrast to the pcDNA.3.1 group. Meanwhile, p27 (Fig. 4) expression was increased in the pcDNA.3.1-HOXA5 group. Moreover, we treated ME-180 and HT-3 cells with SC79 (AKT activator, 0.1-10 $\mu \mathrm{g} / \mathrm{ml}$ ) for $1 \mathrm{~h}$ after HOXA5 overexpression. We found that SC79 $(1-10 \mu \mathrm{g} / \mathrm{ml})$ markedly activated AKT (p-AKT intensity increase) in both the ME-180 and HT-3 cells and the activity on p-AKT was dose-dependent (Fig. 5A). Thus, we measured the protein expression of p27 in ME-180 and HT-3 cells with HOXA5 overexpression and SC79 $(1 \mu \mathrm{g} / \mathrm{ml})$ incubation for $1 \mathrm{~h}$, and the results showed that p27 was obviously downregulated (Fig. 5B). Meanwhile, caspase-3 activity (Fig. 5C) was inhibited and cell viability (Fig. 5D) and invasion (Fig. 5E) 

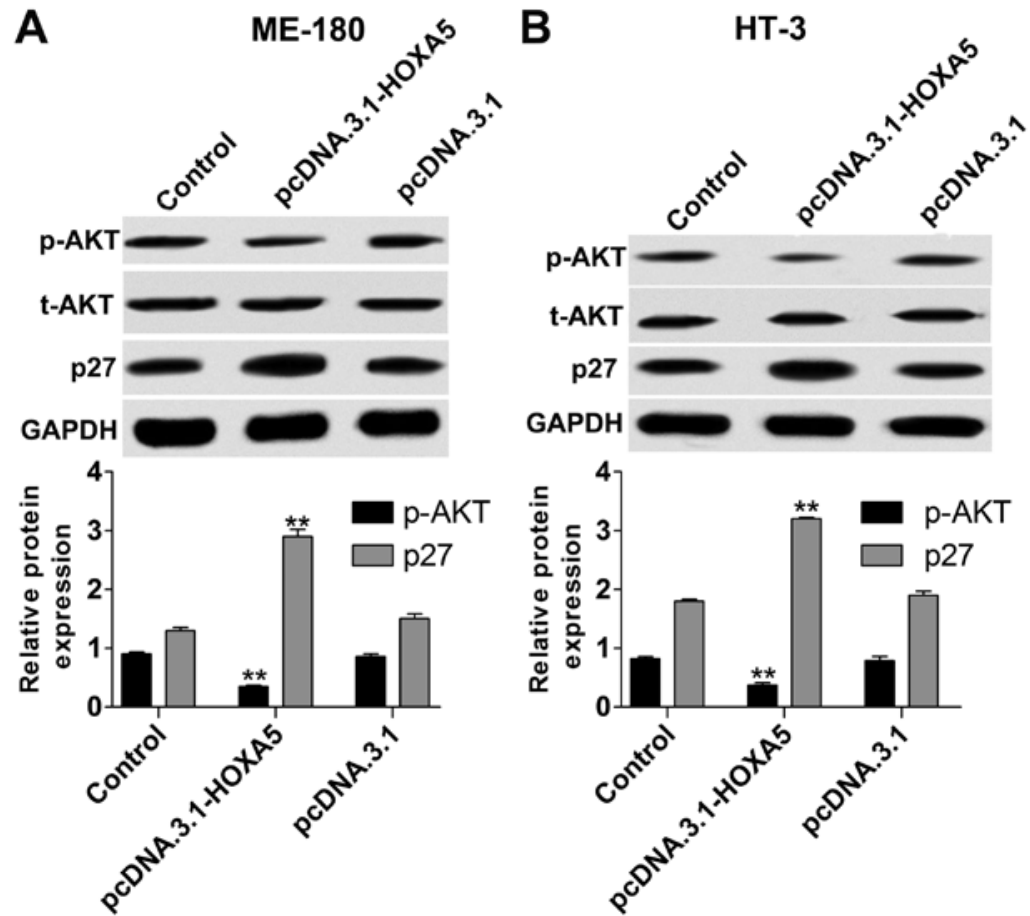

Figure 4. Effect of HOXA5 overexpression on AKT activity and p27 expression in cervical cancer cells. The relative protein levels of p-AKT and p27 were measured by Western blot analyses in ME-180 (A) and HT-3 (B) cells after HOXA5 upregulation. GAPDH was the normalization protein. $\mathrm{n}=3$, ${ }^{* *} \mathrm{P}<0.01$ vs. the pcDNA.3.1 group.

were elevated. Thus, HOXA5 controls cervical cancer cell proliferation and apoptosis via the regulation of $\mathrm{p}-\mathrm{AKT} / \mathrm{p} 27$.

\section{Discussion}

Early symptoms of cervical cancer are not obvious, and the malignant potential in advanced stages reaches a high degree (29). Currently, lack of effective treatment and poor prognosis give rise to the high mortality rate associated with cervical cancer (30). Therefore, the study of the pathogenesis of cervical cancer and the discovery of molecular markers for clinical diagnosis and treatment are crucial to improve the survival of patients with cervical cancer. Studies have demonstrated that HOXA5 plays a significant role in tumor development. The heterotopic expression of HOXA5 was found to promote the proliferation and differentiation of esophageal cancer (31). Zhang et al demonstrated that HOXA5 could constrain cell proliferation via modulating p21 in non-small cell lung cancer (32). Wang et al demonstrated that HOXA5 inhibition by miR-1271 facilitated non-small cell lung cancer cell proliferation and invasion (11). Ectopic expression of HOXA5 was found to induce apoptosis in human liposarcomas (33). Liu et al found that HOXA5 upregulation inhibits the proliferation and promotes apoptosis in K562 leukemia cells (34). However, the role of HOXA5 in cervical cancer is still unclear. In the present study, we found that HOXA5 was suppressed in cervical cancer cell lines and tissues. Overexpression of HOXA5 was achieved by transfection with pcDNA.3.1-HOXA5, which distinctly accelerated caspase-3 activity and cell apoptosis in cervical cancer cell lines. Moreover, HOXA5 overexpression had inhibitory effects on cell viability, proliferation and invasion of cervical cancer cell lines. The role of HOXA5 in cervical cancer was found to be consistent with that in different cancers in the literature mentioned above.

Feng et al found that HOXA5 could restrain AKT activity in the white adipocytes in mice (13). AKT, a proto-oncogene, has a significant regulatory effect on cell proliferation, apoptosis and invasion of cancer cells. Palacios et al found that AKT activation results in chronic lymphocytic leukemia (CLL) B-cell proliferation (35). Yang et al demonstrated that inhibition of AKT activation by Matrine inhibited bladder cancer cell proliferation and invasion in vitro (36). Upregulation of AKT phosphorylation was also found to induce cell growth and invasion in non-small cell lung cancer (37). Targeting of the PI3K/AKT pathway by microRNA-29b promoted the apoptosis of hepatic stellate cells in liver fibrosis (38). Das et al demonstrated that suppression of AKT promoted FOXO3a-dependent apoptosis in prostate cancer (39). Moreover, Jeyamohan et al found that inhibition of the PI3K/Akt signaling pathway could induce cell apoptosis in cervical cancer (40). In the present study, we investigated whether AKT plays a role in the regulation of cervical cancer development by HOXA5. Analysis of the results showed that AKT phosphorylation was suppressed by HOXA5 overexpression in cervical cancer lines. Additionally, AKT activation by SC79 visibly abolished the effect of HOXA5 overexpression on caspase-3 activity, cell apoptosis, cell viability, proliferation and invasion in cervical cancer cell lines. Therefore, AKT plays an important role in the regulation of cervical cancer development by HOXA5.

p27, as a tumor suppressor, has been found to display inhibitory effects on cervical cancer cells. miR-196a was found to elevate cell proliferation via decreasing p27 expression in laryngeal cancer (41). Singh et al reported that resveratrol increases cell apoptosis via the p27 pathway in prostate cancer 
A
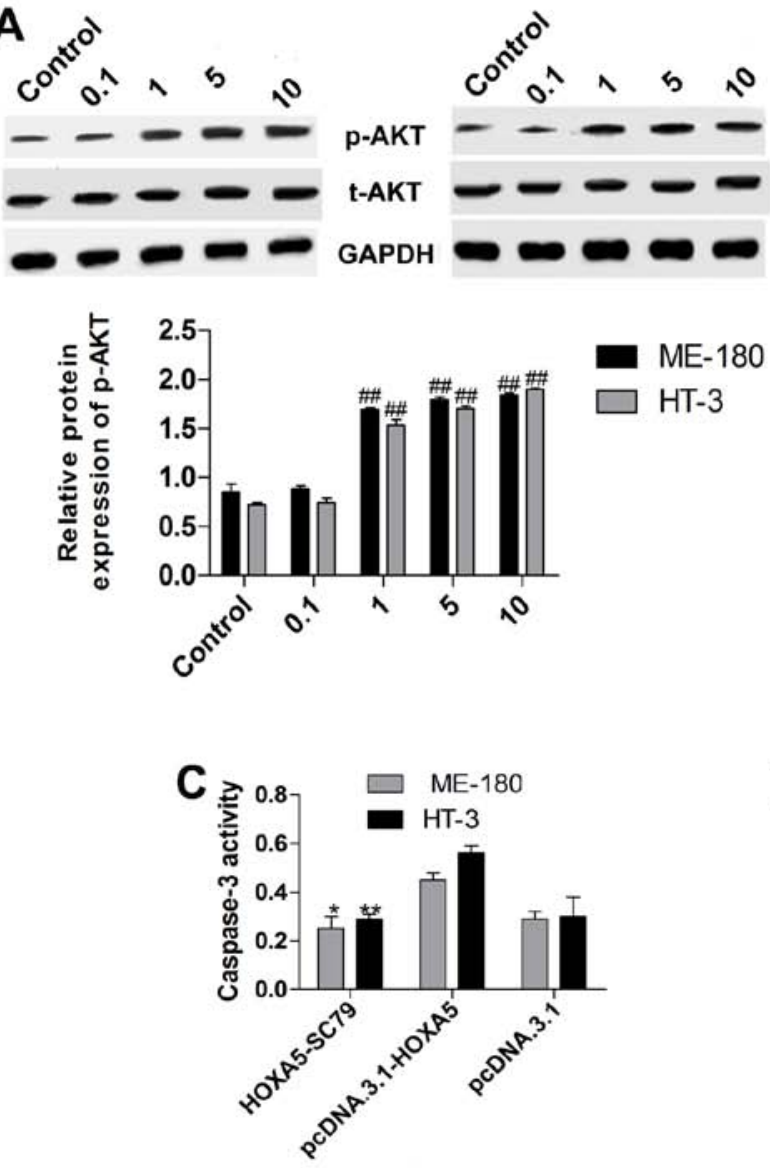

B
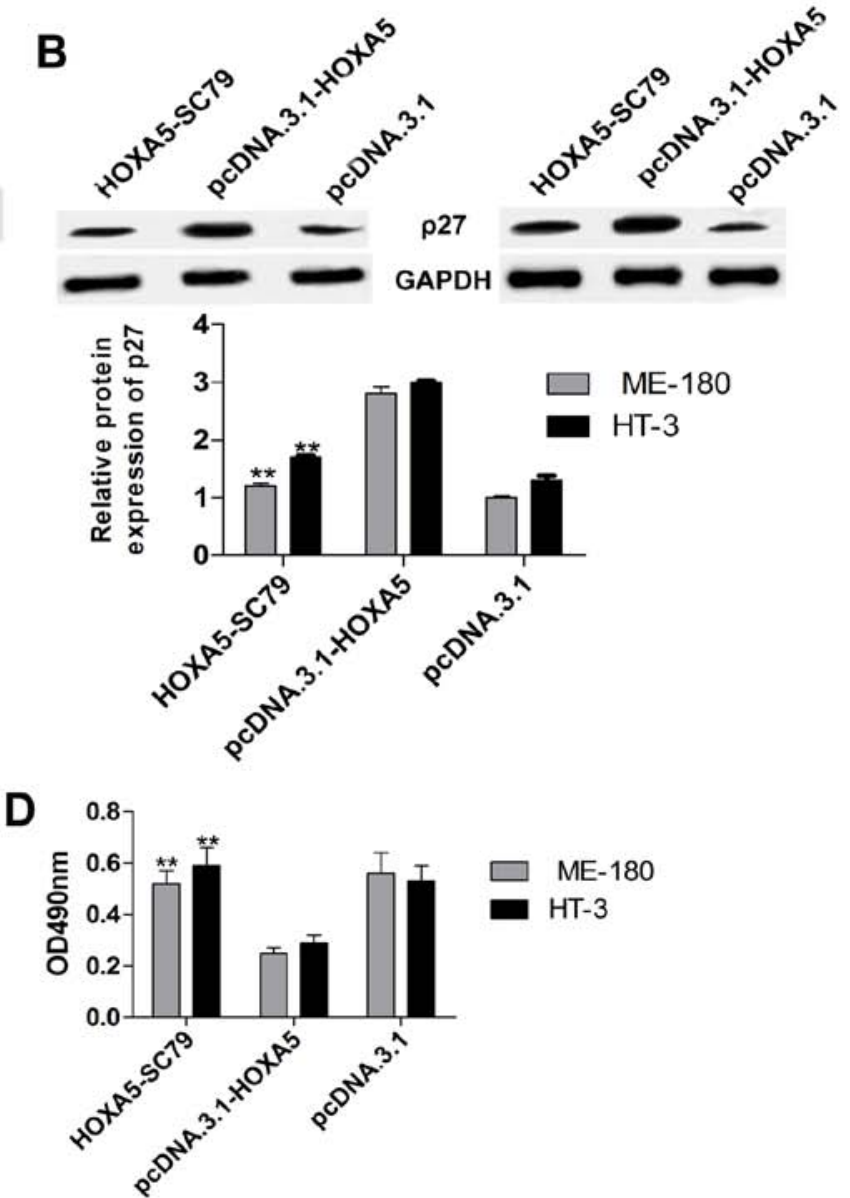
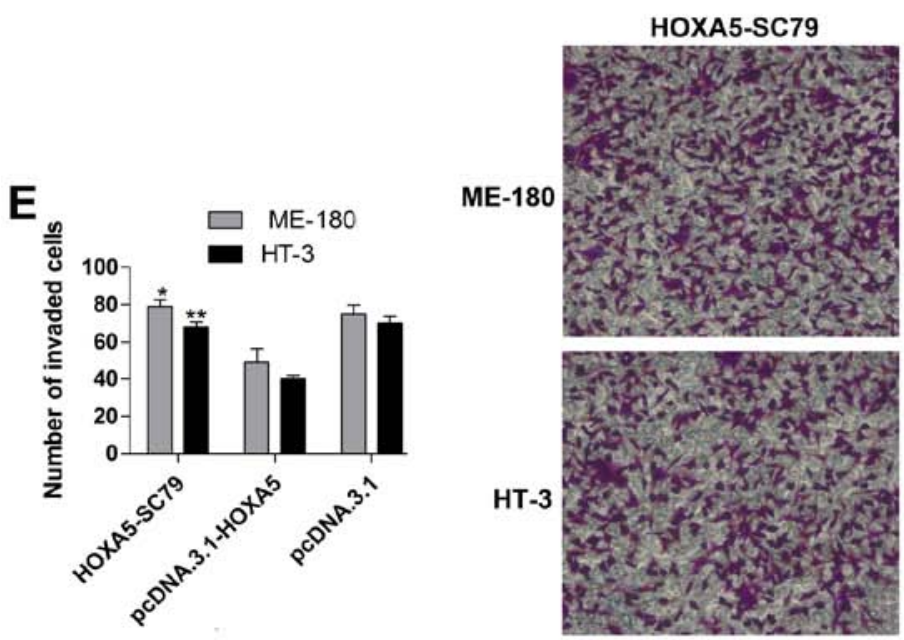

pcDNA.3.1-HOXA5
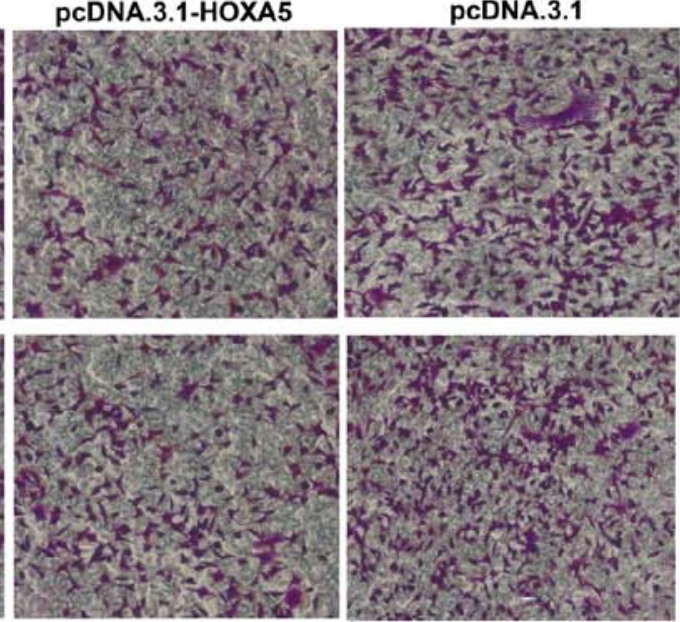

Figure 5. HOXA5 regulates p27 expression via controlling AKT activity. (A) The relative protein levels of p-AKT were measured by western blot analyses in ME-180 and HT-3 cells treated with SC79 (AKT activator, $0.1-10 \mu \mathrm{g} / \mathrm{ml}$ ) for $1 \mathrm{~h}$ after HOXA5 overexpression. 0.1, 1, 5, 10: Cells treated with SC79 $(0.1,1$, $5,10 \mu \mathrm{g} / \mathrm{ml}$ ) for $1 \mathrm{~h}$ after HOXA5 overexpression. $\mathrm{n}=3$, ${ }^{\# \#} \mathrm{P}<0.01 \mathrm{vs}$. the control group. (B) The relative protein levels of $\mathrm{p} 27$ were determined by western blot analyses in ME-180 and HT-3 cells treated with SC79 (AKT activator, $1 \mu \mathrm{g} / \mathrm{ml}$ ) for $1 \mathrm{~h}$ after HOXA5 overexpression. (C) Caspase-3 activity was detected by a kit in ME-180 and HT-3 cells treated with SC79 $(1 \mu \mathrm{g} / \mathrm{ml})$ for $1 \mathrm{~h}$ after HOXA5 overexpression. (D) and (E) Cell proliferation and invasion abilities were separately measured by the MTT and Transwell invasion assays in ME-180 and HT-3 cells treated with SC79 (1 $\mu \mathrm{g} / \mathrm{ml})$ for $1 \mathrm{~h}$ after HOXA5 overexpression. HOXA5-SC79: Cells treated with SC79 $(1 \mu \mathrm{g} / \mathrm{ml})$ for $1 \mathrm{~h}$ after HOXA5 overexpression. $\mathrm{n}=3,{ }^{*} \mathrm{P}<0.05,{ }^{* *} \mathrm{P}<0.01$ vs. the pcDNA.3.1-HOXA5 group.

cells (42). Cui et al showed that upregulation of p27 by Snai2 inhibited the proliferation and tumor formation of human cervical cancer cells (43). It was reported that AKT phosphorylation could elicit p27 transcription in HeLa cells (44). Thus, we assumed that HOXA5 could regulate p27 via controlling AKT phosphorylation in cervical cancer cell lines.
In the present study, data showed that HOXA5 overexpression increased the expression of p27, and inhibited cervical cancer development. In addition, elevation of AKT phosphorylation reversed the effect of HOXA5 upregulation on p27 expression. Therefore, HOXA5 overexpression inhibits cervical cancer development via modulating p-AKT/p27. 
In summary, the results of the present study revealed that HOXA5 is down-regulated in cervical cancer cell lines and tissues. The gain-of-function of HOXA5 markedly decreased cell viability, proliferation and invasion. Meanwhile, HOXA5 overexpression induced caspase-3 activity and increased cell apoptosis in cervical cancer cell lines. Furthermore, overexpression of HOXA5 upregulated p27 expression via controlling the activation of AKT, providing a novel target for the treatment of cervical cancer.

\section{Acknowledgements}

Not applicable.

\section{Funding}

No funding was received.

\section{Availability of data and materials}

The datasets used during the present study are available from the corresponding author upon reasonable request.

\section{Authors' contributions}

ZW designed and prepared the experiments, performed the experiments and wrote the manuscript. CY contributed to the reagents/materials/analysis tools. HW wrote, modified and revised the manuscript and was also involved in the conception of the study. All authors read and approved the manuscript and agree to be accountable for all aspects of the research in ensuring that the accuracy or integrity of any part of the work are appropriately investigated and resolved.

\section{Ethics approval and consent to participate}

This research was approved by the Ethics Committee of The Fourth People's Hospital of Shaanxi. Informed consent was obtained from all of the patients.

\section{Patient consent for publication}

Not applicable.

\section{Competing interests}

The authors declare that they have no competing interests.

\section{References}

1. Munagala R, Aqil F, Jeyabalan J and Gupta RC: Tanshinone IIA inhibits viral oncogene expression leading to apoptosis and inhibition of cervical cancer. Cancer Lett 356: 536-546, 2015.

2. Carter P, Alifrangis C, Cereser B, Chandrasinghe P, Del Bel Belluz L, Fotopoulou C, Frilling A, Herzog T, Moderau N, Tabassum N, et al: Assessing tumor molecular profiling to guide treatments for patients with advanced female genital tract malignancy. Oncotarget 9: 6007-6014, 2017.

3. Ditto A, Martinelli F, Bogani G, Fischetti M, Di Donato V, Lorusso D and Raspagliesi F: Fertility-sparing surgery in early-stage cervical cancer patients: Oncologic and reproductive outcomes. Int J Gynecol Cancer 25: 493-497, 2015.
4. Bao H, Zhang L, Wang L, Zhang M, Zhao Z, Fang L, Cong S, Zhou $M$ and Wang L: Significant variations in the cervical cancer screening rate in China by individual-level and geographical measures of socioeconomic status: A multilevel model analysis of a nationally representative survey dataset. Cancer Med 7: 2089-2100, 2018.

5. Imai T, Satoh I, Matsumoto K, Asada Y, Yamazaki T, Morita S, Saijo S, Okubo JI, Wakamori S, Saijo S and Matsuura K: Retrospective observational study of occult cervical lymph-node metastasis in T1N0 tongue cancer. Jpn J Clin Oncol 47: 130-136, 2017.

6. Hussain I, Bhan A, Ansari KI, Deb P, Bobzean SA, Perrotti LI and Mandal SS: Bisphenol-A induces expression of HOXC6, an estrogen-regulated homeobox-containing gene associated with breast cancer. Biochim Biophys Acta 1849: 697-708, 2015.

7. Kiehl S, Zimmermann T, Savai R, Pullamsetti SS, Seeger W, Bartkuhn $\mathrm{M}$ and Dammann RH: Epigenetic silencing of downstream genes mediated by tandem orientation in lung cancer. Sci Rep 7: 3896, 2017.

8. Wang JL, Qi Z, Li YH, Zhao HM, Chen YG and Fu W: TGF $\beta$ induced factor homeobox 1 promotes colorectal cancer development through activating Wnt/ $\beta$-catenin signaling. Oncotarget 8 : 70214-70225, 2017.

9. Beltran H, Prandi D, Mosquera JM, Benelli M, Puca L, Cyrta J, Marotz C, Giannopoulou E, Chakravarthi BV, Varambally S, et al: Divergent clonal evolution of castration-resistant neuroendocrine prostate cancer. Nat Med 22: 298-305, 2016.

10. Gao F, Liu W, Guo Q, Bai Y, Yang H and Chen H: Physcion blocks cell cycle and induces apoptosis in human B cell precursor acute lymphoblastic leukemia cells by downregulating HOXA5. Biomed Pharmacother 94: 850-857, 2017.

11. Wang Y, Xu L and Jiang L: miR-1271 promotes non-small-cell lung cancer cell proliferation and invasion via targeting HOXA5. Biochem Biophys Res Commun 458: 714-719, 2015.

12. Teo WW, Merino VF, Cho S, Korangath P, Liang X, Wu RC, Neumann NM, Ewald AJ and Sukumar S: HOXA5 determines cell fate transition and impedes tumor initiation and progression in breast cancer through regulation of E-cadherin and CD24. Oncogene 35: 5539-5551, 2016.

13. Feng F, Ren Q, Wu S, Saeed M and Sun C: Hoxa5 increases mitochondrial apoptosis by inhibiting Akt/mTORC1/S6K1 pathway in mice white adipocytes. Oncotarget 8: 95332-95345, 2017.

14. Zhu Q, Lv T, Wu Y, Shi X, Liu H and Song Y: Long non-coding RNA 00312 regulated by HOXA5 inhibits tumour proliferation and promotes apoptosis in Non-small cell lung cancer. J Cell Mol Med 21: 2184-2198, 2017.

15. Ma C, Wu G, Zhu Q, Liu H, Yao Y, Yuan D, Liu Y, Lv T and Song Y: Long intergenic noncoding RNA 00673 promotes non-small-cell lung cancer metastasis by binding with EZH2 and causing epigenetic silencing of HOXA5. Oncotarget 8: 32696-32705, 2017.

16. Takahashi O, Hamada J, Abe M, Hata S, Asano T, Takahashi Y, Tada M, Miyamoto M, Kondo S and Moriuchi T: Dysregulated expression of HOX and ParaHOX genes in human esophageal squamous cell carcinoma. Oncol Rep 17: 753-760, 2007.

17. Paraskevopoulou MD and Tsichlis PN: A perspective on AKT 25-plus years after its discovery. Sci Signal 10: pii: eaan8791, 2017.

18. Li XT, Wang HZ, Wu ZW, Yang TQ, Zhao ZH, Chen GL, Xie XS, Li B, Wei YX, Huang YL, et al: miR-494-3p regulates cellular proliferation, invasion, migration, and apoptosis by PTEN/akt signaling in human glioblastoma cells. Cell Mol Neurobiol 35: 679-687, 2015.

19. Zhang YQ, Wei XL, Liang YK, Chen WL, Zhang F, Bai JW, Qiu SQ, Du CW, Huang WH and Zhang GJ: Over-expressed twist associates with markers of epithelial mesenchymal transition and predicts poor prognosis in breast cancers via ERK and Akt activation. PLoS One 10: e0135851, 2015.

20. Zhang GM, Bao CY, Wan FN, Cao DL, Qin XJ, Zhang HL, Zhu Y, Dai B, Shi GH and Ye DW: MicroRNA-302a suppresses tumor cell proliferation by inhibiting AKT in prostate cancer. PLoS One 10: e0124410, 2015.

21. Yeung CL, Tsang TY, Yau PL and Kwok TT: Human papillomavirus type 16 E6 suppresses microRNA-23b expression in human cervical cancer cells through DNA methylation of the host gene C9orf3. Oncotarget 8: 12158-12173, 2017.

22. Zhao J, Li L and Peng L: MAPK1 up-regulates the expression of MALAT1 to promote the proliferation of cardiomyocytes through PI3K/AKT signaling pathway. Int J Clin Exp Pathol 8: 15947-15953, 2015. 
23. Huang Y, Yoon MK, Otieno S, Lelli M and Kriwacki RW: The activity and stability of the intrinsically disordered Cip/Kip protein family are regulated by non-receptor tyrosine kinases. J Mol Biol 427: 371-386, 2015

24. Wan C, Hou S, Ni R, Lv L, Ding Z, Huang X, Hang Q, He S, Wang Y, Cheng C, et al: MIF4G domain containing protein regulates cell cycle and hepatic carcinogenesis by antagonizing CDK2-dependent p27 stability. Oncogene 34: 237-245, 2015.

25. Huang J, Zhou N, Watabe K, Lu Z, Wu F, Xu M and Mo YY: Long non-coding RNA UCA1 promotes breast tumor growth by suppression of p27 (Kip1). Cell Death Dis 5: e1008, 2014.

26. Narita Y, Nagane M, Mishima K, Huang HJ, Furnari FB and Cavenee WK: Mutant epidermal growth factor receptor signaling down-regulates p27 through activation of the phosphatidylinositol 3-kinase/Akt pathway in glioblastomas. Cancer Res 62 6764-6769, 2002.

27. Li H, Jia Y, Cheng J, Liu G and Song F: LncRNA NCK1-AS1 promotes proliferation and induces cell cycle progression by crosstalk NCK1-AS1/miR-6857/CDK1 pathway. Cell Death Dis 9: 198, 2018.

28. Livak KJ and Schmittgen TD: Analysis of relative gene expression data using real-time quantitative PCR and the 2(-Delta Delta C(T)) method. Methods 25: 402-408, 2001.

29. Mwaka AD, Orach CG, Were EM, Lyratzopoulos G, Wabinga $H$ and Roland M: Awareness of cervical cancer risk factors and symptoms: Cross-sectional community survey in post-conflict northern Uganda. Health Expect 19: 854-867, 2016.

30. Cao S, Liu W, Li F, Zhao W and Qin C: Decreased expression of IncRNA GAS5 predicts a poor prognosis in cervical cancer. Int J Clin Exp Pathol 7: 6776-6783, 2014.

31. Zhang H, Zhao JH and Suo ZM: Knockdown of HOXA5 inhibits the tumorigenesis in esophageal squamous cell cancer. Biomed Pharmacother 86: 149-154, 2017.

32. Zhang ML, Nie FQ, Sun M, Xia R, Xie M, Lu KH and Li W: HOXA5 indicates poor prognosis and suppresses cell proliferation by regulating p21 expression in non small cell lung cancer. Tumour Biol 36: 3521-3531, 2015.

33. Lee DH, Forscher C, Di Vizio D and Koeffler HP: Induction of p53-independent apoptosis by ectopic expression of HOXA5 in human liposarcomas. Sci Rep 5: 12580, 2015.

34. Liu WJ, Zhang T, Guo QL, Liu CY and Bai YQ: Effect of ATRA on the expression of HOXA5 gene in K562 cells and its relationship with cell cycle and apoptosis. Mol Med Rep 13: 4221-4228, 2016.
35. PalaciosF,AbreuC,PrietoD,MorandeP,RuizS,Fernández-CaleroT, Naya H, Libisch G, Robello C, Landoni AI, et al: Activation of the PI3K/AKT pathway by microRNA-22 results in CLL B-cell proliferation. Leukemia 29: 115-125, 2015.

36. Yang Y, Guo JX, Shao ZQ and Gao JP: Matrine inhibits bladder cancer cell growth and invasion in vitro through PI3K/AKT signaling pathway: An experimental study. Asian Pac J Trop Med 10: 515-519, 2017.

37. Fu QF, Liu Y, Fan Y, Hua SN, Qu HY, Dong SW, Li RL, Zhao MY, Zhen Y, Yu XL, et al: Alpha-enolase promotes cell glycolysis, growth, migration, and invasion in non-small cell lung cancer through FAK-mediated PI3K/AKT pathway. J Hematol Oncol 8: 22, 2015.

38. Wang J, Chu ES, Chen HY, Man K, Go MY, Huang XR, Lan HY, Sung JJ and Yu J: microRNA-29b prevents liver fibrosis by attenuating hepatic stellate cell activation and inducing apoptosis through targeting PI3K/AKT pathway. Oncotarget 6: 7325-7338, 2015.

39. Das TP, Suman S, Alatassi H, Ankem MK and Damodaran C: Inhibition of AKT promotes FOXO3a-dependent apoptosis in prostate cancer. Cell Death Dis 7: e2111, 2016.

40. Jeyamohan S, Moorthy RK, Kannan MK and Arockiam AJ: Parthenolide induces apoptosis and autophagy through the suppression of PI3K/Akt signaling pathway in cervical cancer. Biotechnol Lett 38: 1251-1260, 2016.

41. Jin C, Zhang Y and Li J: Upregulation of MiR-196a promotes cell proliferation by downregulating p $27^{\mathrm{kip} 1}$ in laryngeal cancer. Biol Res 49: 40, 2016.

42. Singh SK, Banerjee S, Acosta EP, Lillard JW and Singh R Resveratrol induces cell cycle arrest and apoptosis with docetaxel in prostate cancer cells via a p53/ p $21^{\mathrm{WAF} / \mathrm{CIP1}}$ and $\mathrm{p} 27^{\mathrm{KIPl}}$ pathway. Oncotarget 8: 17216-17228, 2017.

43. Cui N, Yang WT and Zheng PS: Slug inhibits the proliferation and tumor formation of human cervical cancer cells by up-regulating the $\mathrm{p} 21 / \mathrm{p} 27$ proteins and down-regulating the activity of the Wnt/ $\beta$-catenin signaling pathway via the trans-suppression Akt1/p-Akt1 expression. Oncotarget 7: 26152-26167, 2016.

44. Dan HC, Sun M, Yang L, Feldman RI, Sui XM, Ou CC, Nellist M, Yeung RS, Halley DJ, Nicosia SV, et al: Phosphatidylinositol 3-kinase/Akt pathway regulates tuberous sclerosis tumor suppressor complex by phosphorylation of tuberin. J Biol Chem 277: 35364-35370, 2002. 